\title{
Structural elucidation of the red dye obtained from reaction of 1,8- naphthalenediol with 1,1-diphenylprop-2-yn-1-ol. A correction.
}

\author{
Luis M. Carvalho ${ }^{\mathrm{a}}$, Artur M. S. Silva ${ }^{\mathrm{b}}$, Cristina I. Martins ${ }^{\mathrm{a}}$, \\ Paulo J. Coelho ${ }^{* a}$ and Ana M.F. Oliveira-Campos ${ }^{c}$
}

${ }^{a}$ Dept. Química, Universidade de Trás-os-Montes e Alto Douro, 5001-911 Vila Real, Portugal

${ }^{b}$ Dept. Química, Universidade de Aveiro, 3810-193 Aveiro, Portugal

${ }^{\mathrm{c} C}$ Centro de Química, IBQF, Universidade do Minho, 4700-320 Braga, Portugal

\begin{abstract}
The structure of the intensely coloured red product obtained through the reaction of 1,8-naphthalenediol with 1,1-diphenylprop-2-yn-1-ol was reinvestigated. Instead of the expected permanent open form of the naphthopyran, the dye presents the $\alpha, \beta$-unsaturated chain at a different position of the naphthalene nucleus. The structure of this compound was elucidated on the basis of detailed spectral analysis, including 2D NMR experiments.
\end{abstract}

Key Words: naphthopyrans; 1,8-naphthalenediol; dye; hydrogen-bond.

\section{Introduction}

The reaction of naphthols with 1,1-diarylprop-2-yn-1-ols under acid catalysis gives naphthopyrans in medium yield. The accepted mechanism involves the in situ formation of an aryl propynyl ether which undergoes a Claisen rearrangement followed by enolization, sigmatropic [1,7] H-shift and finally an electrocyclic ring closure (Scheme 1$)^{1}{ }^{1}$

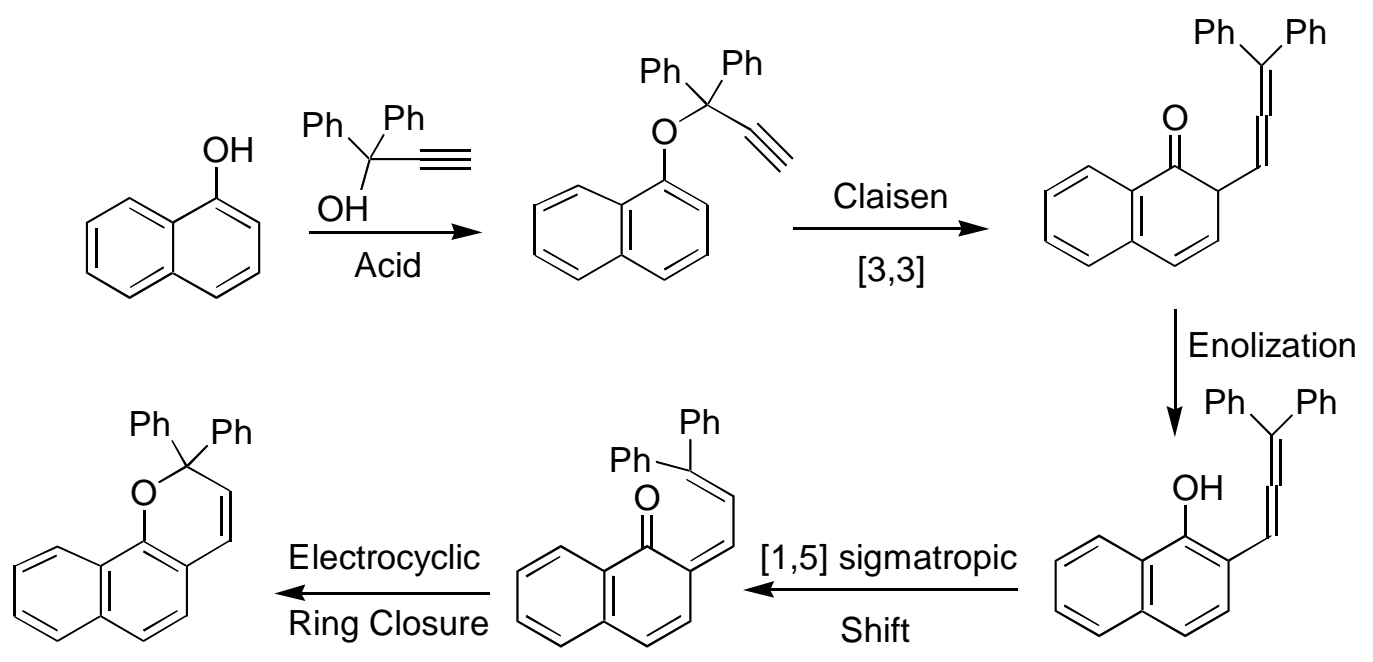

Scheme 1. 
There is a considerable interest in these compounds as they exhibit a photochromic behaviour at room temperature, in solution or in polymeric matrices. ${ }^{2}$ Under near-UV irradiation, a reversible ring opening reaction takes place, leading to a highly conjugated coloured form (Scheme 2).

Scheme 2.<smiles>C1=CC(c2ccccc2)(c2ccccc2)Oc2c1ccc1ccccc21</smiles>

Closed form (Colourless)<smiles>O=C1/C(=C/C=C(c2ccccc2)c2ccccc2)C=Cc2ccccc21</smiles>

Open form (Coloured)

In a recent study, we reported that the reaction of 1,8-naphthalenediol with 1,1-diphenylprop-2-yn1-ol under pyridinium p-toluenesulphonate (PPTS) catalysis gave a highly coloured red dye in 65\% yield. ${ }^{3}$ No naphthopyrans were found in the reaction mixture. Spectroscopic analysis $\left({ }^{1} \mathrm{H}\right.$ and ${ }^{13} \mathrm{C}$ NMR, IV, UV, HRMS) of the product was consistent with structure $\mathbf{B}$, indicating that the product could be a naphthopyran open form, stabilised through an intramolecular H-bond (Scheme 3). ${ }^{3}$<smiles>Oc1cccc2cccc(O)c12</smiles>

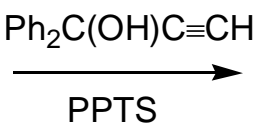

$65 \%$

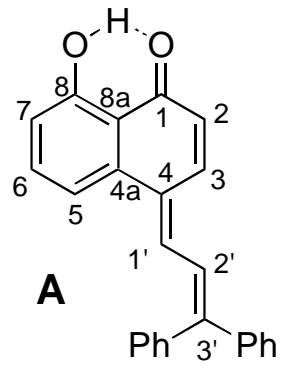<smiles>O=C1/C(=C/C=C(c2ccccc2)c2ccccc2)C=Cc2cccc(O)c21</smiles>

B

Scheme 3.

A more detailed structural study was achieved by further long range correlations observed in bidimensional NMR studies and revealed that the correct structure for the product is in fact the paraisomer A. To decide whether structure $\mathbf{A}$ or structure $\mathbf{B}$ corresponds to the product is not a straightforward task because almost all the NMR spectral data (Table 1) can be assigned considering both structures.

The key-feature was found in the HMBC spectrum where a cross peak between the signal $\delta_{\mathrm{H}} 7.10$ (H-5) and a quaternary carbon signal at $\delta_{\mathrm{C}} 128.5(\mathrm{C}-4)$ requires that the $\alpha, \beta$-unsaturated chain must be located at this carbon (Fig. 1). Further information that supported the position of the $\alpha, \beta$ unsaturated chain was obtained from NOE experiments which are also listed in Table 1. The observed effects between the signals $\delta_{\mathrm{H}} 7.10(\mathrm{H}-5)$ and $\delta_{\mathrm{H}} 7.68(\mathrm{H}-1)$ confirms the spatial proximity of these protons as depicted in Fig. 1, excluding the possibility of structure $\mathbf{B}$. 
Table 1. NMR spectral data of the red dye $\mathbf{A}$

\begin{tabular}{|c|c|c|c|c|c|}
\hline Atom & ${ }^{1} \mathrm{H}(\mathrm{J}$ in $\mathrm{Hz})$ & ${ }^{13} \mathrm{C}$ & ${ }^{1} \mathrm{H}-{ }^{1} \mathrm{H}$ COSY & HMBC & NOESY \\
\hline 1 & - & 190.0 & - & - & - \\
\hline 2 & $6.56, d d\left(10.0,1.4^{*}\right)$ & 126.3 & $\mathrm{H}-3, \mathrm{H}-1$ ' & C-4, C-8a & $\mathrm{H}-3$ \\
\hline 3 & 8.09, br $d(10.0)$ & 137.1 & $\mathrm{H}-2$ & C-1, C-4, C-4a, C1' & H-2, H-2' \\
\hline 4 & - & $128.5 \S$ & - & - & - \\
\hline $4 a$ & - & 136.9 & - & - & - \\
\hline 5 & 7.10, brd (8.0) & 112.8 & H-6 & C-4, C-6, C-7, C-8a & H-6, H-1' \\
\hline 6 & 7.38, $d d(8.0)$ & 134.1 & $\mathrm{H}-5, \mathrm{H}-7$ & C-4a, C-5, C-8, C-8a & $\mathrm{H}-5, \mathrm{H}-7$ \\
\hline 7 & 6.93, br d (8.1) & 116.2 & H-6 & C-5, C-8, C-8a & H-6 \\
\hline 8 & - & 162.5 & - & - & - \\
\hline $8 a$ & - & 115.9 & - & - & - \\
\hline $1^{\prime}$ & 7.68, br d (12.2) & 136.6 & H-2, H-2’ & C-3, C-4a, C-3' & H-5, H-2' \\
\hline $2^{\prime}$ & 7.53, br d (12.2) & 122.3 & $\mathrm{H}-1{ }^{\prime}$ & C-4 & $\mathrm{H}-3, \mathrm{H}-1$ ' \\
\hline $3^{\prime}$ & - & 153.3 & - & - & - \\
\hline$-\mathrm{OH}$ & $13.29, s$ & - & - & C-7, C-8, C-8a & - \\
\hline
\end{tabular}

All ${ }^{1} \mathrm{H}_{-}{ }^{13} \mathrm{C}$ connectivities were assigned by HSQC experiments. NOE difference experiments confirmed the following spatial correlations: H-2 with H-3; H-3 with H-2 and H-2'.

$\S$ Approximate value due to overlapped signals.

* Long range coupling $\left({ }^{5} \mathrm{~J}\right)$

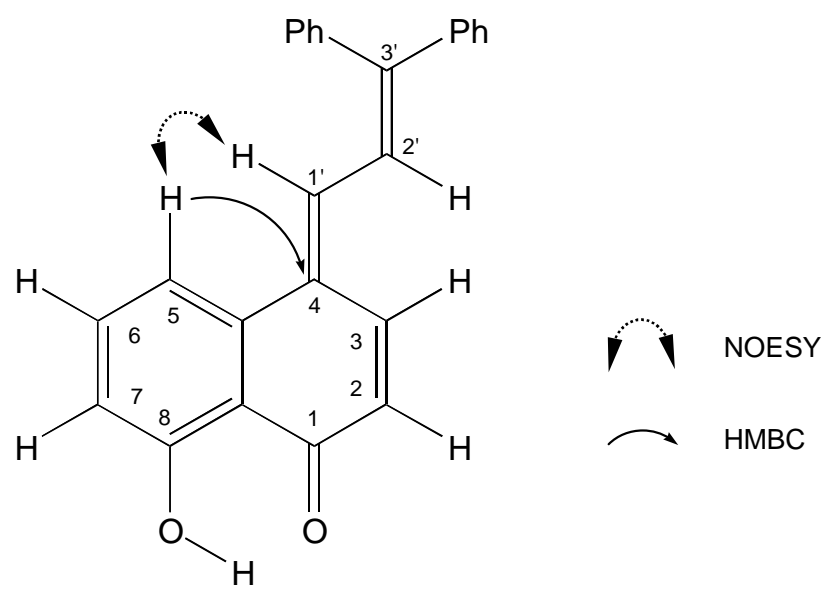

Fig. 1. Revealing $\mathrm{C} / \mathrm{H}$ and $\mathrm{H} / \mathrm{H}$ long-range correlations obtained from the HMBC and NOESY spectra.

Recently, Heron et al reported that the reaction of 1-naphthol with 1,1-diphenylprop-2-yn-1-ol under APTS catalysis gives, in addition to the expected naphthopyran, $1 \%$ of a coloured dye with the conjugated system at C-4 of the naphthalene nucleus. When starting from 2-methyl-1-naphthol, which cannot give the naphthopyran product, the yield was improved to $19 \%{ }^{4}$ The authors suggested a mechanism involving the electrophilic aromatic substitution of the naphthol by the allenyl cation derived from a Meyer-Schuster rearrangement of the 1,1-diarylprop-2-yn-1-ol. ${ }^{5}$ 
The absence of the usual naphthopyran product in the reaction of 1,8-naphthalenediol with 1,1diphenylprop-2-yn-1-ol can be explained by the intramolecular H-bond between the two hydroxylic substituents which may prevent the formation of the intermediate arylpropynyl ether that leads to the naphthopyran. It is possible that the red dye $\mathbf{A}$ is formed through the mechanism proposed by Heron (Scheme 4), but it is not clear why the product from the para attack of the allenyl cation to the naphthalene nucleus is the only one observed.

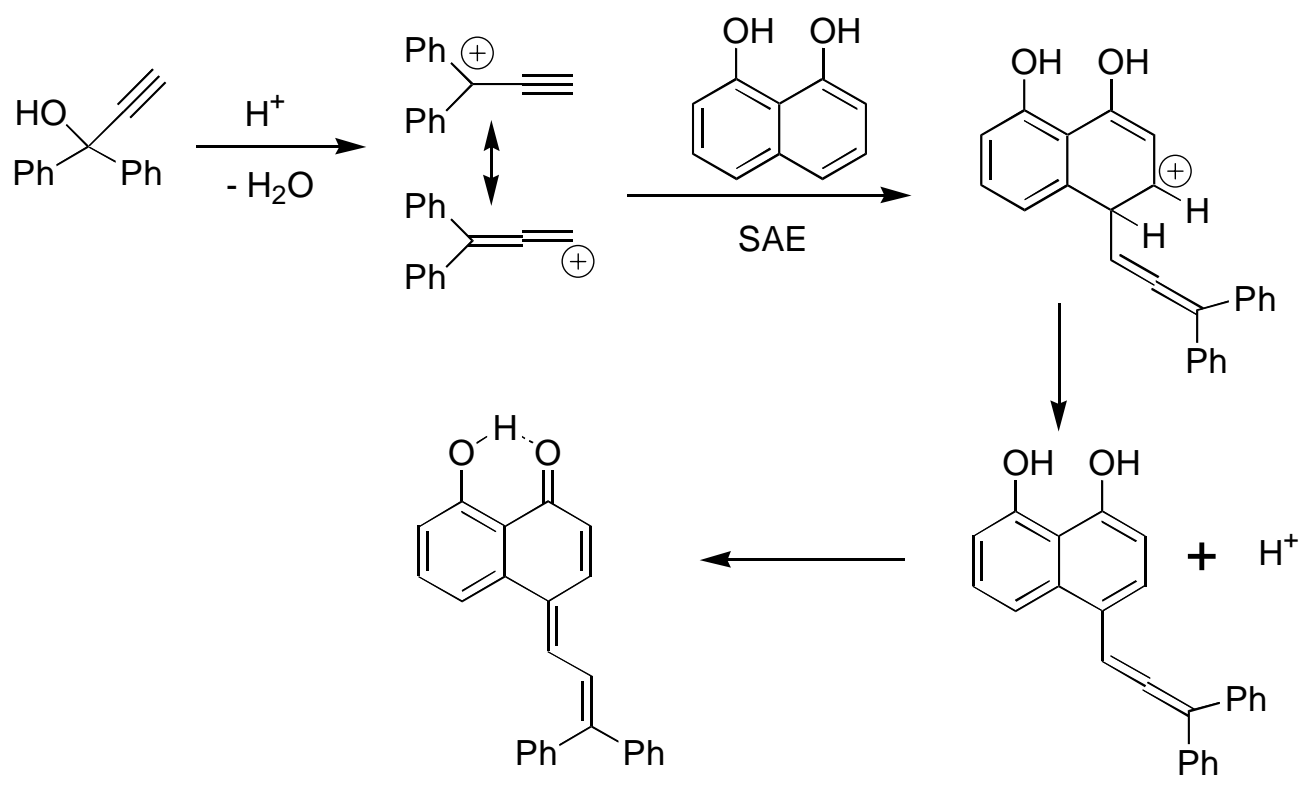

Scheme 4.

\section{Acknowledgments}

We would like to thank FCT (Portugal's Foundation for Science and Technology) for financial support through project Praxis XXI/P/QUI/10021/1998.

\section{References}

1- Zindely, J. ; Schmid, H. Helv. Chim. Acta., 1968, 51, 1510.

2- Van Gemert, B. In Organic Photochromic and Thermochromic Compounds;, Crano J.C. and Guglielmetti R.J., Kluwer Academic / Plenum Publishers, New York, 1999; Vol. 1, pp. 111140, Chapter 3.

3- Martins, C. I. ; Coelho, P. J. ; Carvalho, L. M. ; Oliveira-Campos A. M. F., Tetrahedron Lett. 2002, 43, 2203-2205

4- Heron, B. M.; Thomas, D. A.; Proceedings of the $9^{\text {th }}$ International Conference on Dyes and Pigments, Colorchem 2002, Špindleruv Mlýn, Czech Republic.

5- Gabbutt, C. D.; Hepworth, J. D.; Heron, B. M.; Partington, S. M.; Thomas, D. A. Dyes Pigments 2001, 49, 65-74. 